\title{
Diabetes is an independent predictor of survival 17 years after myocardial infarction: follow-up of the TRACE registry
}

\author{
Thomas Kümler*1, Gunnar H Gislason², Lars Køber ${ }^{1}$ and Christian Torp-Pedersen²
}

\begin{abstract}
Background: In patients hospitalized for myocardial infarction, there are limited data examining the long-term prognostic effect of diabetes.

The aim of this study was to systematically evaluate the development of diabetes as an independent long-term prognostic factor after myocardial infarction.

Methods: Prospective follow-up of 6676 consecutive MI patients screened for entry in the Trandolapril Cardiac Evaluation (TRACE) study. The patients were analysed by Kaplan-Meier survival analysis, landmark analysis and Cox proportional hazard models and outcome measure was all-cause mortality.

Results: The mortality in patients with diabetes was $82,7 \%$ at 10 years of follow-up and $91,1 \%$ at 15 years of follow-up, while patients without diabetes had a mortality of $60,2 \%$ at 10 years of follow-up and $72,9 \%$ at 15 years of follow-up ( $p$ $<0.0001$ ). Landmark analysis continued to show prognostic significance of diabetes throughout the duration of followup. Multivariable Cox proportional-hazards model showed that the hazard ratio for death in patients with diabetes overall was 1.47 (95\% confidence intervals (Cl) 1.35-1.61) and varied between 1.19 (Cl 1.04-1.37) and 2.13 (Cl 1.33-3.42) in the 2-year periods of follow-up.
\end{abstract}

Conclusions: Diabetes is an important independent long-term prognostic factor after $\mathrm{Ml}$ and continues to predict mortality even 17 years after index MI.

This underscores the importance of aggressive diagnostic and therapeutic approach in diabetes patients with MI.

\section{Background}

Disturbances in glucose metabolism are frequent in patients with ischemic heart disease, and abnormal glucose tolerance in MI patients is almost twice as common as hypertension and dyslipidemia [1]. The Glucose Metabolism in Patients with Acute Myocardial Infarction (GAMI) study documented a high prevalence of diabetes and abnormal glucose tolerance in patients $\mathrm{MI}$ and no known diabetes [2]. Diabetes increases long-term mortality following MI $[3,4]$, and patients requiring glucoselowering therapy exhibit a cardiovascular risk of the same magnitude as patients without diabetes with a prior myocardial infarction, regardless of gender and diabetes type

* Correspondence: tkumler@dadlnet.dk

1 Department of Cardiology, Rigshopitalet University Hospital, Blegdamsvej, Copenhagen, Denmark

Full list of author information is available at the end of the article
[5]. As a result, patients with diabetes should receive prophylactic treatment for cardiovascular disease, but many remain undiagnosed thus missing this treatment effect [6]. Moreover, the most recent guidelines recommend that patients with myocardial infarction are screened for diabetes, including an oral glucose tolerance test when necessary, but this recommendation is new and not widely followed [7]. As a result, it is important to know whether diabetes as an important risk factor does not deteriorate over time even when cardiovascular disease is established, underlining the importance of an aggressive approach towards diagnosing diabetes in MI patients. However, data examining the long-term prognostic effect of diabetes after MI are scarce, and there is lack of information in the variation of the prognostic effect of diabetes over time in MI patients. 
We undertook a retrospective study of 6676 consecutive patients admitted with myocardial infarction and screened for entry in the TRACE study. The purpose was to systematically evaluate the long-term development of the prognostic importance of diabetes as a risk factor evaluated at the time of the index infarction.

\section{Methods}

\section{Subject and study design}

The Trandolapril Cardiac Evaluation (TRACE) registry has been described in detail previously $[8,9]$. In brief, the TRACE registry consist of the $6676 \mathrm{MI}$ patients screened for entry in the TRACE study, which was a double-blind, randomized, parallel group, placebo-controlled study of trandolapril versus placebo in patients with left ventricular dysfunction after MI. The study was conducted in 27 centres in Denmark, and participating centres were required to screen consecutive patients admitted with MI 2-6 days after the infarction and provide data on each patient for the registry. The diagnostic criteria of myocardial infarction were chest pain and/or electrocardiographic changes suggestive of ischemia or infarction, accompanied with elevated cardiac enzymes. Left ventricular systolic function was evaluated in a core lab as wall motion index using a 9-segment model and a reverse scoring system. Wall motion index multiplied by 30 approximates left ventricular ejection fraction. The technique has previously been described in detail and validated [10]. Of the screened patients, 1749 (26.2\%) were randomised to trandolapril or placebo in the TRACE study.

The TRACE study was approved by all regional ethical committees in Denmark and complies with the 1975 Declaration of Helsinki. Informed consent was obtained from each patient. The study was registered with the National Board of Health and the Danish Data Protection Agency. All participating patients provided informed consent.

\section{Follow-up data}

All Danish citizens are given a unique and permanent person registry number. All deaths in Denmark are registered in the central person registry within 2 weeks and all deaths are confirmed by a death certificate. Follow-up mortality data were provided by a computerized analysis from the Danish Central Personal Registry by 16.06.2008.

\section{Statistical analysis}

The base-line characteristics of the study population were compared with a t-test for continuous variables and a chi-square test for discrete variables. Mortality was analyzed with Kaplan-Meier curves. We used Landmark analyses to illustrate the prognostic significance of diabetes in 2-year intervals. Relative risk for death and the associated 95 percent confidence intervals were calcu- lated as hazard ratios derived from a Cox proportionalhazards regression model. We used stepwise models including increasing number of variables. The models fulfilled the Cox regression model assumptions (linearity of continuous variables, proportional hazards assumption and lack of interaction) unless otherwise specified. Statistical analyses were performed with the Statistical Analysis System, ver. 9.1 (SAS Institute, Cary, NC, USA).

\section{Results}

\section{Baseline characteristics}

A total of 7001 MI's in 6676 patients were reported from May 1990 to August 1992. By the end of follow-up, the mortality was 5231 patients $(78.4 \%) .38$ patients $(0.56 \%)$ were lost to follow-up or emigrated and were censured on the last day they were known to be alive.

Baseline characteristics of the 6668 patients included in our study are listed in table 1 . There were missing data on diabetes status on 8 patients. Patients with diabetes were older, had more co-morbidity and risk factors, received more often diuretics but less often thrombolytic therapy, had poorer left ventricular function and were in higher New York Heart Association (NYHA) and Killip class. All the mentioned differences were statistically significant.

At the start of the study, there were 156 (2.34\%) patients with diabetes treated with diet, 372 (5.58\%) with diabetes treated with oral medication, and $140(2.10 \%)$ with patients with diabetes treated with insulin. There were missing data on treatment in 5 patients.

\section{Analysis of all-cause mortality}

As expected, patients with diabetes had a significantly higher mortality than patients without diabetes (figure 1, unadjusted analysis). The mortality in patients with diabetes was $82,7 \%$ and $91,1 \%$ at 10 and 15 years of follow-up while patients without diabetes had a mortality of $60,2 \%$ and $72,9 \%$ at 10 and 15 years of follow-up (p value < 0.0001 for difference between patients with and without diabetes). To clarify the importance of diabetes as a prognostic factor we performed landmark analysis illustrating survival in diabetics and non diabetics adjusted for age, sex and wall motion index in 2 year intervals after the infarction (Figure 2). The Landmark analysis demonstrated that diabetes continued to have a significant prognostic effect throughout the duration of follow-up.

We constructed Cox proportional-hazards models of total mortality with stepwise addition of covariates (Table 2). Age was a significant prognostic factor throughout the length of follow-up in all models. The hazard ratio (HR) varied between 1.45 (95\% Confidence Interval [CI] 1.371.54) and 2.14 (CI 1.68-2.71) per 10 years increase in patient age in the model incorporating all covariates. For the entire follow-up period, diabetes was a significant prognostic factor, hazard ratio 1.47 (CI 1.35-1.61) 
Table 1: Patient characteristics according to diabetes classification.

\begin{tabular}{|c|c|c|c|}
\hline & Diabetes $(n=719)$ & No diabetes $(n=5949)$ & P Value \\
\hline Age (SD) & 69.5 & 67.1 & $<0.0001$ \\
\hline Gender. \% & 41.3 & 31.5 & $<0.0001$ \\
\hline Women & 58.7 & 68.5 & \\
\hline \multicolumn{4}{|l|}{ Men } \\
\hline Body mass index (SD) & 26.7 & 25.6 & $<0.0001$ \\
\hline Creatinine (mean). $\mu \mathrm{mol} / \mathrm{I}$ & 117 & 107 & $<0.0001$ \\
\hline Hypertension. \% & 36.3 & 21.0 & $<0.0001$ \\
\hline Angina pectoris $\%$ & 48.1 & 35.5 & $<0.0001$ \\
\hline Previous MI. \% & 32.3 & 22.3 & $<0.0001$ \\
\hline Heart failure*. \% & 69.0 & 51.8 & $<0.0001$ \\
\hline Current smoking. $\%$ & 36.1 & 53.4 & $<0.0001$ \\
\hline Thrombolysis. \% & 27.0 & 42.5 & $<0.0001$ \\
\hline Previous stroke. \% & 13.2 & 7.6 & $<0.0001$ \\
\hline Diuretic treatment. \% & 64.2 & 42.3 & $<0.0001$ \\
\hline \multicolumn{4}{|l|}{ NYHA. \% } \\
\hline Class I & 47.0 & 58.4 & $<0.0001$ \\
\hline Class II & 34.8 & 28.3 & \\
\hline Class III & 6.9 & 3.9 & \\
\hline Class IV & 9.0 & 6.3 & \\
\hline \multicolumn{4}{|l|}{ Killip. \% } \\
\hline Class I & 69.5 & 79.9 & $<0.0001$ \\
\hline Class II & 22.0 & 14.2 & \\
\hline Class III & 2.2 & 2.11 & \\
\hline Class IV & 6.3 & 3.8 & \\
\hline \multicolumn{4}{|l|}{ Wall motion index. \% } \\
\hline$>1.6$ & 21.1 & 34.1 & $<0.0001$ \\
\hline $1.3-1.6$ & 20.9 & 23.9 & \\
\hline $0.8-1.2$ & 40.1 & 31.1 & \\
\hline$<0.8$ & 8.2 & 4.7 & \\
\hline
\end{tabular}

SD, standard deviation; NYHA, New York Heart Association;

P-values calculated with the use of chi2-test for discrete variables and t-test for continuous variables.

*History of heart failure and in-hospital heart failure

adjusted for all covariates. Greater significance of diabetes reflected in a higher hazard ratio was observed in the end of follow-up, however this did not reach statistical significance in the last period of follow-up, most likely as a result of lack of statistical power since only few patients with diabetes were still alive at this time. Relative risks in the model without covariates (model 1) and with all covariates (model 3) in each of the 2-year periods of follow-up are illustrated in figure 3. HR for diabetes varied between 1.19 (CI 1.04-1.37) and 2.13 (CI 1.33-3.42) in the fully adjusted models and reached significance in most of the 2 -year intervals. The hazard ratio associated with male gender was between 0.99 (CI 0.89-1.10) and 1.64 (CI 1.27-2.12) and did not reach statistical significance in most of the 2-year interval. Overall, male gender was associated with a small, but significant increase in risk of death, hazard ratio 1.11 (CI 1.04-1.18).

\section{Discussion}

This study describes the long-term prognostic significance of diabetes in a large population of consecutive patients with MI. With a follow-up of 17 years, we found that diabetes continued to represent a strong independent prognostic factor for all-cause mortality. This is a 


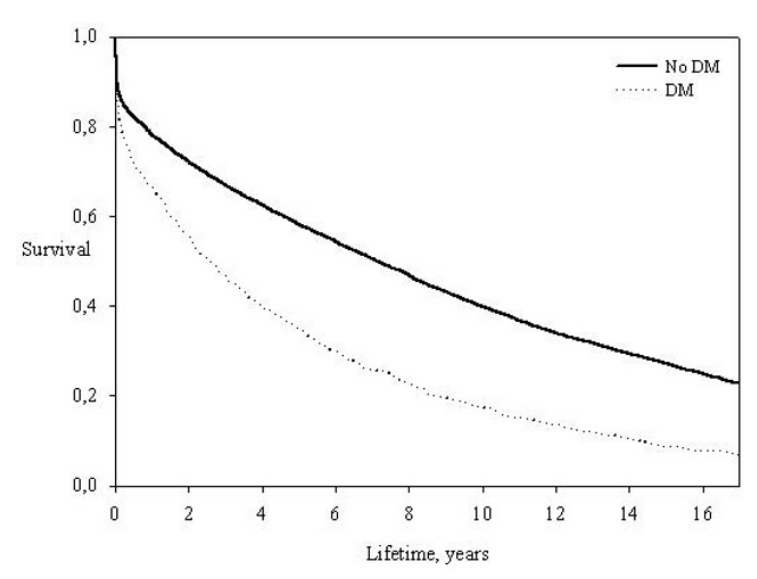

Figure 1 Unadjusted all-cause mortality stratified by diabetes.

plausible result from a biological point of view as diabetes is a progressive and chronic disease.

Previous studies has documented that diabetes is a well described predictor for an adverse outcome following myocardial infarction [11]. Even patients with pre-diabetic conditions have an elevated risk of cardiovascular disease [12], and it seems a progressive threshold between blood glucose and cardiovascular risk exist, also below the diabetic threshold [13]. Our results expand on these findings by documenting continued prognostic importance of diabetes with a follow-up period much longer than any other study of this subject. In addition, our results support a previous analysis of some of the same patients suggesting that the magnitude of the prognostic effect of diabetes may increase with time [4]. These new results combined with the knowledge of many undiagnosed and thus untreated patients with diabetes under-

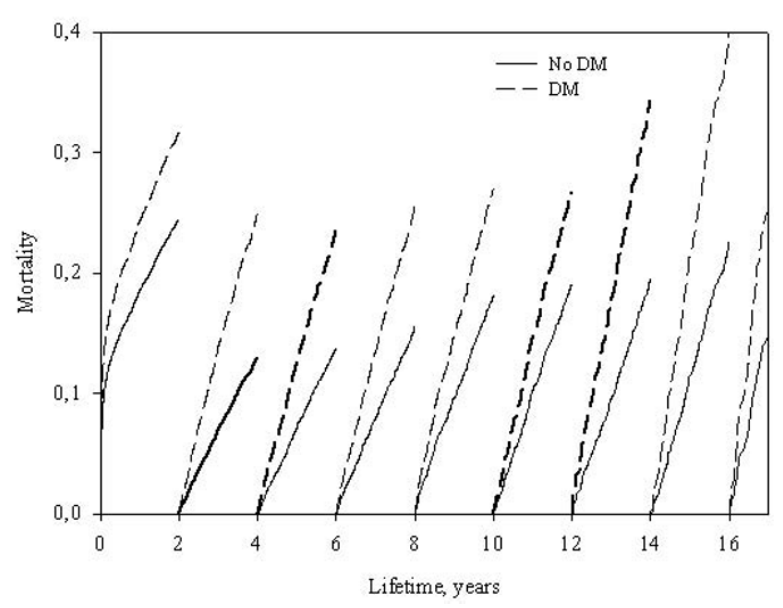

Figure 2 Landmark analysis of the time dependent prognostic significance of diabetes adjusted for age and gender. scores the necessity of an aggressive approach towards diagnosing diabetes in MI patients.

It has been suggested that the glucometabolic state at the time of admission for MI confers long-term prognostic information in patients with and without diabetes [14], which would mean that elevated blood glucose level at admission with MI is not only a negligible expression of acute physiological stress. This hypothesis is supported by the observation that both in patients with and without diabetes, blood glucose concentration at the time of admission is related to the risk of death in patients admitted with MI [15]. These studies underscore the close relationship between abnormal glucose metabolism and ischemic heart disease which could be explained by more extensive atherosclerosis in diabetic patients, a theory supported by some, but not all studies [16,17]. Another theory hypothesizes that metabolic disturbance could have an adverse effect in the process of myocardial infarction. This was tested in trials where MI patients with diabetes where treated intensively with insulin to better glycemic status. One trial showed an improvement in long-term mortality but no effect on short term mortality [18]. Another trial failed to show any benefit of the intervention, but epidemiological analysis confirmed that glucose level was a strong predictor of long-term mortality, suggesting that glucose control is important [19]. A smaller study showed no difference in mortality between intervention and control group [20]. In conclusion, no definitive effect of intensive treatment has been documented.

Of great interest is whether long-term intensive diabetes treatment after discharge can lower the risk of developing new cardiovascular events. Epidemiological studies and meta-analyses have shown a clear relationship between haemoglobin $\mathrm{A} 1 \mathrm{C}$ and the frequency of cardiovascular disease [21,22], and large studies have suggested beneficial effects of intensive glucose regulation on the risk of cardiovascular events, but such an effect has not been clearly defined [23,24]. Recently, 3 large randomized clinical studies failed to document an effect of intensive glucose regulation on cardiovascular events [25-27].

Despite the lack of evidence for the effect of intensive glucose regulation on cardiovascular events, we believe there are several reasons why a more aggressive approach to diagnosing diabetes is warranted. First, earlier diagnoses would have great significance for risk stratification by identifying patients at high risk. Second, initiation of earlier and more widespread medical treatment would be possible. Improved prognosis would result, since the effect of intensive glucose regulation on micro vascular complications are well documented [23,24], as is multiple risk factor intervention [28]. Third, the lack of documented effect of intensive glucose regulation on cardiovascular events in randomized trials could have other 
Table 2: Proportional hazards models of mortality as a function of time

\begin{tabular}{|c|c|c|c|c|c|c|c|c|c|c|c|c|c|c|c|c|c|c|}
\hline \multirow[b]{2}{*}{ Variables } & \multicolumn{2}{|c|}{$0-2$ years } & \multicolumn{2}{|c|}{ 2-4 years } & \multicolumn{2}{|c|}{ 4-6 years } & \multicolumn{2}{|c|}{ 6-8 years } & \multicolumn{2}{|c|}{ 8-10 years } & \multicolumn{2}{|c|}{$10-12$ years } & \multicolumn{2}{|c|}{$12-14$ years } & \multicolumn{2}{|c|}{$14-16$ years } & \multicolumn{2}{|c|}{+16 years } \\
\hline & $\mathbf{R R}$ & $\mathrm{Cl}^{*}$ & $\mathbf{R R}$ & $\mathrm{Cl}^{*}$ & $\mathbf{R R}$ & $\mathrm{Cl}^{*}$ & $\mathbf{R R}$ & $\mathrm{Cl}^{*}$ & $\mathbf{R R}$ & $\mathrm{Cl}^{*}$ & $\mathbf{R R}$ & $\mathrm{Cl}^{*}$ & $\mathbf{R R}$ & $\mathrm{Cl}^{*}$ & $\mathbf{R R}$ & $\mathrm{Cl}^{*}$ & $\mathbf{R R}$ & $\mathrm{Cl}^{*}$ \\
\hline \multicolumn{19}{|c|}{ Model 1} \\
\hline Diabetes & 1.76 & $1.56-1.98$ & 2.36 & $1.93-2.89$ & 1.98 & $1.54-2.55$ & 1.88 & $1.41-2.50$ & 1.66 & $1.19-2.32$ & 1.43 & $0.96-2.15$ & 1.92 & $1.26-2.91$ & 1.84 & $1.15-2.93$ & 1.50 & $0.66-3.40$ \\
\hline \multicolumn{19}{|c|}{ Model 2} \\
\hline Male gender & 1.03 & $0.94-1.13$ & 1.36 & $1.15-1.60$ & 1.02 & $0.85-1.22$ & 1.23 & $1.01-1.49$ & 1.19 & $0.97-1.46$ & 1.60 & $1.26-2.03$ & 1.05 & $0.82-1.34$ & 1.04 & $0.80-1.35$ & 1.05 & $0.71-1.55$ \\
\hline $\mathrm{Age}^{* *}$ & 1.86 & $1.77-1.95$ & 2.02 & $1.86-2.20$ & 1.90 & $1.72-2.08$ & 2.08 & $1.90-2.30$ & 2.08 & $1.88-2.30$ & 2.12 & $1.90-2.39$ & 2.14 & $1.88-2.43$ & 1.99 & $1.72-2.28$ & 2.12 & $1.71-2.62$ \\
\hline Diabetes & 1.57 & $1.39-1.77$ & 2.21 & $1.81-2.71$ & 1.87 & $1.46-2.41$ & 1.86 & $1.39-2.48$ & 1.67 & $1.20-2.33$ & 1.49 & $0.99-2.24$ & 1.97 & $1.30-3.00$ & 2.00 & $1.26-3.19$ & 1.69 & $0.74-3.85$ \\
\hline \multicolumn{19}{|c|}{ Model $3^{* * *}$} \\
\hline Male gender & 0.99 & $0.89-1.10$ & 1.29 & $1.08-1.54$ & 1.03 & $0.85-1.24$ & 1.31 & $1.07-1.61$ & 1.08 & $0.87-1.34$ & 1.64 & $1.27-2.12$ & 1.05 & $0.80-1.37$ & 1.11 & $0.82-1.49$ & 0.99 & $0.64-1.53$ \\
\hline $\mathrm{Age}^{* *}$ & 1.45 & $1.37-1.54$ & 1.71 & $1.55-1.88$ & 1.69 & $1.52-1.86$ & 1.88 & $1.69-2.10$ & 1.90 & $1.69-2.10$ & 1.99 & $1.74-2.24$ & 1.97 & $1.71-2.28$ & 1.90 & $1.64-2.20$ & 2.14 & $1.68-2.71$ \\
\hline Diabetes & 1.19 & $1.04-1.37$ & 1.92 & $1.54-2.38$ & 1.66 & $1.27-2.17$ & 1.57 & $1.16-2.12$ & 1.34 & $0.94-1.90$ & 1.40 & $0.91-2.16$ & 2.09 & $1.37-3.20$ & 2.13 & $1.33-3.42$ & 1.86 & $0.80-4.32$ \\
\hline
\end{tabular}

*95\% confidence interval
${ }^{* *}$ Risk ratio associated with an increase in age of 10 years.

***Other covariates in model 3: Body mass index, previous AMl, angina pectoris, creatinine, congestive heart failure, diabetes mellitus, wall motion index, systemic hypertension, thrombolytic therapy. 


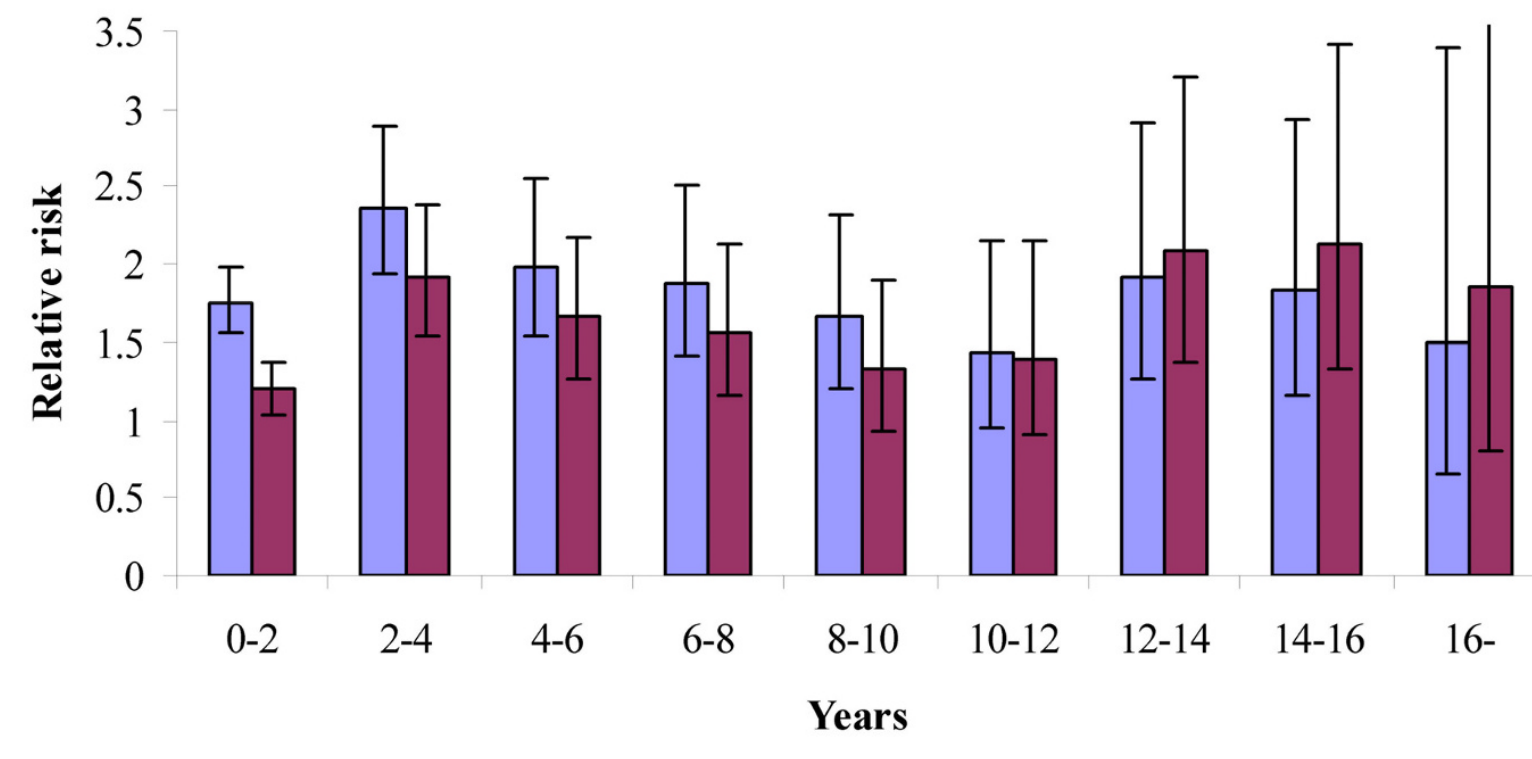

Figure 3 All cause mortality hazard ratio as a function of follow-up time for Cox proportional hazards model 1 (diabetes) and 3 (all covariates).

explanations. The effect of intensive glucose treatment could be modest in comparison with the well documented effect of treating other risk factors and thus difficult to document unless in longer trials with higher event rate. The randomized trials have compared usual care diabetes regulation with intensive regulation, but it is still possible that cardiovascular events could be prevented when comparing poor regulation with good regulation. The population included in randomized trials had greater presence of atherosclerosis suggested by long diabetes duration, multiple risk factors or known cardiovascular disease. Subset analyses have shown benefit of intensive diabetes regulation in patients with lesser presence of atherosclerosis [29]. Current strategies for regulation of diabetes could have opposing effects on risk of cardiovascular disease.

Our study has some limitations that need to be acknowledged. When patients were screened for entry into the TRACE study, thrombolytic therapy was administered routinely to ST-elevation MI patients. The standard treatment today in Denmark is percutaneous coronary intervention. Moreover, almost all MI patients today receive clopidogrel, statins and beta-blockers. Some receive spironolactone or eplerenone. New pharmacological treatment combinations are today available to patients with diabetes. The most recent guidelines state that patients with diabetes and albuminuria or hypertension should be treated with an ACE inhibitor or an angiotensin receptor blocker, even when the left ventricular systolic function is normal [30]. This was not the case at the start of the TRACE study, probably resulting in an under-treatment of patients with diabetes during the TRACE study period and the start of the follow-up. These changes in the management of patients with MI and diabetes could significantly influence our results. However, a multivariable analysis from 1975 to the end of 2003 reveal only slight improvement in post discharge survival after MI [31], but this is probably explained by a lack of multivariate adjustment for MI complications, medical and interventional treatment, as the survivors had more aggressive treatment and fewer complications. An important point is that we do not have information regarding the medical treatment of patients with and without diabetes during the follow-up period and thus can not analyse potential differences. Since a number of patients without diabetes at the time of the infarction have developed diabetes later, the observed difference between patients with and without diabetes is smaller than the actual difference.

Many data shows that the diagnosis and treatment of diabetes in cardiovascular patients is not adequately done. New guidelines recommend oral glucose tolerance test in patients with myocardial infarction but this is not formally implemented. Our study is important as it 
underlines the importance of pinpointing the effect of diabetes as a long-term prognostic factor in MI patients. To our knowledge, this is the first study to systematically evaluate the time-dependent development of diabetes as a long-term prognostic factor in consecutive MI patients with a follow-up of up to 17 years. The population described here was recruited from 27 Danish hospitals with regional patient uptake and can be considered to be representative of patients with MI admitted alive in a western industrialized country. By documenting the continued prognostic importance of diabetes as a prognostic factor in patients with ischemic heart disease, our results supports an aggressive approach towards diagnosing diabetes.

\section{Conclusions}

Diabetes is a long-term negative prognostic factor in MI patients that continues to influence prognosis for up to 17 years after MI. This underscores the importance of an aggressive diagnostic approach towards diabetes. The presence of diabetes identifies MI patients at high-risk, whom are candidates for continued aggressive medical therapy.

\section{Competing interests}

The authors declare that they have no competing interests.

\section{Authors' contributions}

TK was responsible for all stages of the study with the exception of data collection and follow-up: Analysis of data, analysis of the literature, and preparation of the manuscript.

GG supervised the entire study, participated in follow-up, analysis and interpretation of data, and revised the manuscript.

LK supervised the entire study, participated in follow-up, analysis and interpretation of data, and revised the manuscript.

CTP conceived the idea for the study, supervised the study, collected data, analyzed data and revised the manuscript.

All authors have seen and approved the manuscript.

\section{Acknowledgements}

Rikke Sørensen, M.D., for help with SAS programming.

\section{Author Details}

'Department of Cardiology, Rigshopitalet University Hospital, Blegdamsvej, Copenhagen, Denmark and 2Department of Cardiology, Gentofte University Hospital, Niels Andersens Vej 65, Copenhagen, Denmark

Received: 2 May 2010 Accepted: 2 June 2010

Published: 2 June 2010

\section{References}

1. Bartnik M, Malmberg K, Hamsten A, Efendic S, Norhammar A, Silveira A, Tenerz A, Ohrvik J, Ryden L: Abnormal glucose tolerance--a common risk factor in patients with acute myocardial infarction in comparison with population-based controls. J Intern Med 2004, 256(4):288-297.

2. Norhammar A, Tenerz A, Nilsson G, Hamsten A, Efendic S, Ryden L, Malmberg K: Glucose metabolism in patients with acute myocardial infarction and no previous diagnosis of diabetes mellitus: a prospective study. Lancet 2002, 359(9324):2140-2144.

3. Janszky I, Hallqvist J, Ljung R, Ahlbom A, Hammar N: Prognostic role of the glucometabolic status assessed in a metabolically stable phase after a first acute myocardial infarction: the SHEEP study. J Intern Med 2008.
4. Melchior T, Kober L, Madsen CR, Seibaek M, Jensen GV, Hildebrandt P, Torp-Pedersen C: Accelerating impact of diabetes mellitus on mortality in the years following an acute myocardial infarction. TRACE Study Group. Trandolapril Cardiac Evaluation. European heart journal 1999, 20(13):973-978

5. Schramm TK, Gislason GH, Kober L, Rasmussen S, Rasmussen JN Abildstrom SZ, Hansen ML, Folke F, Buch P, Madsen M, et al.: Diabetes patients requiring glucose-lowering therapy and nondiabetics with a prior myocardial infarction carry the same cardiovascular risk: a population study of 3.3 million people. Circulation 2008, 117(15):1945-1954.

6. King H, Aubert RE, Herman WH: Global burden of diabetes, 1995-2025: prevalence, numerical estimates, and projections. Diabetes Care 1998, 21(9):1414-1431.

7. Van de Werf F, Bax J, Betriu A, Blomstrom-Lundqvist C, Crea F, Falk V, Filippatos G, Fox K, Huber K, Kastrati A, et al:: Management of acute myocardial infarction in patients presenting with persistent STsegment elevation: the Task Force on the Management of ST-Segment Elevation Acute Myocardial Infarction of the European Society of Cardiology. European heart journal 2008, 29(23):2909-2945.

8. Kober L, Torp-Pedersen C, Carlsen JE, Bagger H, Eliasen P, Lyngborg K, Videbaek J, Cole DS, Auclert L, Pauly NC: A clinical trial of the angiotensin-converting-enzyme inhibitor trandolapril in patients with left ventricular dysfunction after myocardial infarction. Trandolapril Cardiac Evaluation (TRACE) Study Group. N Eng/ J Med 1995, 333(25):1670-1676.

9. The TRAndolapril Cardiac Evaluation (TRACE) study: rationale, design, and baseline characteristics of the screened population. The Trace Study Group. Am J Cardiol 1994, 76(10):44C-50C

10. Kober L, Torp-Pedersen C, Carlsen J, Videbaek R, Egeblad H: An echocardiographic method for selecting high risk patients shortly after acute myocardial infarction, for inclusion in multi-centre studies (as used in the TRACE study). TRAndolapril Cardiac Evaluation. European heart journal 1994, 15(12):1616-1620.

11. Mak KH, Moliterno DJ, Granger CB, Miller DP, White HD, Wilcox RG, Califf RM, Topol EJ: Influence of diabetes mellitus on clinical outcome in the thrombolytic era of acute myocardial infarction. GUSTO-I Investigators. Global Utilization of Streptokinase and Tissue Plasminogen Activator for Occluded Coronary Arteries. J Am Coll Cardiol 1997, 30(1):171-179.

12. Glucose tolerance and mortality: comparison of WHO and American Diabetes Association diagnostic criteria. The DECODE study group. European Diabetes Epidemiology Group. Diabetes Epidemiology: Collaborative analysis Of Diagnostic criteria in Europe. Lancet 1999, 354(9179):617-621.

13. Coutinho M, Gerstein HC, Wang Y, Yusuf S: The relationship between glucose and incident cardiovascular events. A metaregression analysis of published data from 20 studies of 95,783 individuals followed for 12.4 years. Diabetes Care 1999, 22(2):233-240.

14. Norhammar AM, Ryden L, Malmberg K: Admission plasma glucose. Independent risk factor for long-term prognosis after myocardial infarction even in nondiabetic patients. Diabetes Care 1999, 22(11):1827-1831.

15. Capes SE, Hunt D, Malmberg K, Gerstein HC: Stress hyperglycaemia and increased risk of death after myocardial infarction in patients with and without diabetes: a systematic overview. Lancet 2000, 355(9206):773-778

16. Granger CB, Califf RM, Young S, Candela R, Samaha J, Worley S, Kereiakes DJ, Topol EJ: Outcome of patients with diabetes mellitus and acute myocardial infarction treated with thrombolytic agents. The Thrombolysis and Angioplasty in Myocardial Infarction (TAMI) Study Group. J Am Coll Cardiol 1993, 21(4):920-925.

17. Waller BF, Palumbo PJ, Lie JT, Roberts WC: Status of the coronary arteries at necropsy in diabetes mellitus with onset after age 30 years. Analysis of 229 diabetic patients with and without clinical evidence of coronary heart disease and comparison to 183 control subjects. Am J Med 1980, 69(4):498-506.

18. Malmberg K, Ryden L, Efendic S, Herlitz J, Nicol P, Waldenstrom A, Wede $H$, Welin L: Randomized trial of insulin-glucose infusion followed by subcutaneous insulin treatment in diabetic patients with acute myocardial infarction (DIGAMI study): effects on mortality at 1 year. $J$ Am Coll Cardiol 1995, 26(1):57-65. 
19. Malmberg K, Ryden L, Wedel H, Birkeland K, Bootsma A, Dickstein K, Efendic S, Fisher M, Hamsten A, Herlitz J, et al.: Intense metabolic control by means of insulin in patients with diabetes mellitus and acute myocardial infarction (DIGAMI 2): effects on mortality and morbidity. European heart journal 2005, 26(7):650-661.

20. Cheung NW, Wong VW, McLean M: The Hyperglycemia: Intensive Insulin Infusion in Infarction (HI-5) study: a randomized controlled trial of insulin infusion therapy for myocardial infarction. Diabetes Care 2006, 29(4):765-770.

21. Selvin E, Marinopoulos S, Berkenblit G, Rami T, Brancati FL, Powe NR, Golden SH: Meta-analysis: glycosylated hemoglobin and cardiovascular disease in diabetes mellitus. Ann Intern Med 2004, 141(6):421-431.

22. Stettler C, Allemann S, Juni P, Cull CA, Holman RR, Egger M, Krahenbuhl S, Diem P: Glycemic control and macrovascular disease in types 1 and 2 diabetes mellitus: Meta-analysis of randomized trials. Am Heart J 2006, 152(1):27-38

23. Effect of intensive blood-glucose control with metformin on complications in overweight patients with type 2 diabetes (UKPDS 34). UK Prospective Diabetes Study (UKPDS) Group. Lancet 1998, 352(9131):854-865

24. Intensive blood-glucose control with sulphonylureas or insulin compared with conventional treatment and risk of complications in patients with type 2 diabetes (UKPDS 33). UK Prospective Diabetes Study (UKPDS) Group. Lancet 1998, 352(9131):837-853.

25. Duckworth W, Abraira C, Moritz T, Reda D, Emanuele N, Reaven PD, Zieve FJ, Marks J, Davis SN, Hayward R, et al:: Glucose control and vascular complications in veterans with type 2 diabetes. N Engl J Med 2009, 360(2):129-139.

26. Gerstein HC, Miller ME, Byington RP, Goff DC Jr, Bigger JT, Buse JB, Cushman WC, Genuth S, Ismail-Beigi F, Grimm RH Jr, et al.: Effects of intensive glucose lowering in type 2 diabetes. NEngl J Med 2008, 358(24):2545-2559.

27. Patel A, MacMahon S, Chalmers J, Neal B, Billot L, Woodward M, Marre M, Cooper M, Glasziou P, Grobbee D, et al.: Intensive blood glucose control and vascular outcomes in patients with type 2 diabetes. N Eng/ J Med 2008, 358(24):2560-2572.

28. Gaede P, Vedel P, Parving HH, Pedersen O: Intensified multifactorial intervention in patients with type 2 diabetes mellitus and microalbuminuria: the Steno type 2 randomised study. Lancet 1999, 353(9153):617-622.

29. Skyler JS, Bergenstal R, Bonow RO, Buse J, Deedwania P, Gale EA, Howard BV, Kirkman MS, Kosiborod M, Reaven P, et al.: Intensive glycemic control and the prevention of cardiovascular events: implications of the ACCORD, ADVANCE, and VA diabetes trials: a position statement of the American Diabetes Association and a scientific statement of the American College of Cardiology Foundation and the American Heart Association. Circulation 2009, 119(2):351-357.

30. Executive summary: standards of medical care in diabetes--2009. Diabetes Care 2009, 32(Suppl 1):S6-12.

31. Botkin NF, Spencer FA, Goldberg RJ, Lessard D, Yarzebski J, Gore JM: Changing trends in the long-term prognosis of patients with acute myocardial infarction: a population-based perspective. Am Heart J 2006, 151(1):199-205.

\section{doi: $10.1186 / 1475-2840-9-22$}

Cite this article as: Kümler et al., Diabetes is an independent predictor of survival 17 years after myocardial infarction: follow-up of the TRACE registry Cardiovascular Diabetology 2010, 9:22

\section{Submit your next manuscript to BioMed Central and take full advantage of:}

- Convenient online submission

- Thorough peer review

- No space constraints or color figure charges

- Immediate publication on acceptance

- Inclusion in PubMed, CAS, Scopus and Google Scholar

- Research which is freely available for redistribution

Submit your manuscript at www.biomedcentral.com/submit
C BioMed Central 